\title{
Synthesis and Thermoelectric Properties of Partially Double-Filled Skutterudites $\left(\mathrm{La}_{1-\mathrm{z}} \mathrm{Yb}_{\mathrm{z}}\right)_{0.8} \mathrm{Fe}_{4-\mathrm{x}} \mathrm{Co}_{\mathbf{x}} \mathrm{Sb}_{12}$
}

\author{
Ye-Eun Cha and Il-Ho Kim* \\ Department of Materials Science and Engineering, Korea National University of Transportation, Chungju 27469, Republic of Korea
}

\begin{abstract}
Partially double-filled skutterudites were prepared via encapsulated melting and hot pressing processes. The skutterudite phase was successfully synthesized through partial double filling of La/ Yb and substitution of Co. A small quantity of secondary phase (marcasite $\mathrm{FeSb}_{2}$ ) was formed, but its formation was suppressed by increasing Co charge compensation. The marcasite phase was detected in all specimens, which was because charge compensation was not sufficiently performed owing to the partial filling with low valence ions of $\mathrm{La}^{3+}$ and $\mathrm{Yb}^{2+/ 3+}$. Hot-pressed specimens showed relative densities higher than 97.4\% compared to the theoretical density. The calculated lattice constant ranged from 0.9129 to $0.9142 \mathrm{~nm}$. As the contents of La and Co increased, the lattice constants decreased; thus, the filling and substitution were confirmed. The electrical conductivity decreased and the Seebeck coefficient increased with increasing La filling and Co substitution. The thermal conductivity significantly decreased with increasing Co substitution, and was further slightly lowered with increasing La filling. $\left(\mathrm{La}_{0.75} \mathrm{Yb}_{0.25}\right)_{0.8} \mathrm{Fe}_{3} \mathrm{CoSb}_{12}$ yielded a maximum Seebeck coefficient of $168.2 \mathrm{\mu VK}^{-1}$ at $823 \mathrm{~K}$, a maximum power factor of $2.67 \mathrm{mWm}^{-1} \mathrm{~K}^{-2}$ at $723 \mathrm{~K}$, and the lowest thermal conductivity of $2.09 \mathrm{Wm}^{-1} \mathrm{~K}^{-1}$ at $323 \mathrm{~K}$. As a result, $\left(\mathrm{La}_{0.75} \mathrm{Yb}_{0.25}\right)_{0.8} \mathrm{Fe}_{3} \mathrm{CoSb}_{12}$ exhibited the highest dimensionless figure of merit, $\mathrm{ZT}=0.66$ at $823 \mathrm{~K}$.
\end{abstract}

(Received September 16, 2019; Accepted October 21, 2019)

Keywords: thermoelectric, skutterudite, partial double filling, charge compensation

\section{INTRODUCTION}

Thermoelectricity is a technology that directly converts thermal energy into electrical energy or electrical energy into thermal energy. The thermoelectric conversion efficiency is evaluated by a dimensionless figure of merit, $\mathrm{ZT}=\alpha^{2} \sigma \kappa^{-1} \mathrm{~T}$, where $\alpha$ is the Seebeck coefficient, $\sigma$ is the electrical conductivity, $\kappa$ is the thermal conductivity, and $\mathrm{T}$ is the absolute temperature [1]. Two main methods are used to improve ZT and obtain high conversion efficiency. The first is to increase the power factor $\left(\alpha^{2} \sigma\right)$ and the second is to decrease the thermal conductivity. The thermal conductivity is composed of two contributions: lattice thermal conductivity $\left(\kappa_{\mathrm{L}}\right)$ and electronic thermal conductivity $\left(\kappa_{\mathrm{E}}\right)$. These components can be separated using the Wiedemann-Franz law $\left(\kappa_{\mathrm{E}}=\mathrm{L} \sigma \mathrm{T}\right)$, where $\mathrm{L}$ is the Lorenz number [2]. As the

- 차예은: 석사과정, 김일호: 교수

*Corresponding Author: Il-Ho Kim

[Tel: +82-43-841-5380, E-mail: ihkim@ut.ac.kr]

Copyright (c) The Korean Institute of Metals and Materials carrier concentration increases, the electrical conductivity and electronic thermal conductivity increase, but the Seebeck coefficient decreases. Specifically, because the power factor has a trade-off relationship between the electrical conductivity and Seebeck coefficient, the reduction in thermal conductivity should be achieved through the reduction in lattice thermal conductivity. However, the parameters cannot be controlled independently because the thermal conductivity increases along with the electrical conductivity $[3,4]$.

Skutterudite has a body-centered cubic structure with the space group $\operatorname{Im} \overline{3}$, and its unit cell is assembled in the form of $8 \mathrm{MX}_{3}$ with 32 atoms, where $\mathrm{M}$ is the transition element and $\mathrm{X}$ is the pnicogen element [5]. There are two voids per unit cell of the skutterudite, and p-type $\mathrm{RFe}_{4} \mathrm{Sb}_{12}$-based and n-type $\mathrm{RCo}_{4} \mathrm{Sb}_{12}$-based filled skutterudites have been studied, where $\mathrm{R}$ is the rattler filled with alkali, alkaline-earth, or rareearth atoms. The filled skutterudite induces phonon scattering of rattlers in the lattice to reduce the lattice thermal conductivity [6,7]. However, similar to $\mathrm{RFe}_{4} \mathrm{Sb}_{12}$, it is 
difficult to obtain a high thermoelectric performance as the hole concentration is very high and the Seebeck coefficient is relatively low. In addition, $\left[\mathrm{Fe}_{4} \mathrm{Sb}_{12}\right]$ is unstable owing to deficient valence electrons, thus four electrons are required to stabilize the skutterudite phase [8]. The skutterudite can be stabilized in the form $\mathrm{R}^{4+}\left[\mathrm{Fe}_{4} \mathrm{Sb}_{12}\right]^{4-}$ by filling the voids with $\mathrm{R}^{4+}$ ions; however, most elements used as fillers exist with valences of $\mathrm{R}^{2+}$ and $\mathrm{R}^{3+}$, as a result, the valence electrons are insufficient [9]. Thus, charge compensation is required and this is fulfilled by substituting $\mathrm{Co}$ or $\mathrm{Ni}$ at the Fe site [10]. Several studies on phase stabilization and improved thermoelectric performance of the p-type $\mathrm{RFe}_{4} \mathrm{Sb}_{12}$ have been reported, and the thermoelectric properties may be enhanced by reducing the lattice thermal conductivity through single or multiple fillings with charge compensation [11-14]. In particular, filling two or more rare-earth elements with heavy atomic masses greatly reduces the lattice thermal conductivity through phonon scatterings with lower and broader resonance frequencies $[6,15,16]$. In this study, we prepared p-type $\left(\mathrm{La}_{1-\mathrm{z}} \mathrm{Yb}_{\mathrm{z}}\right)_{0.8} \mathrm{Fe}_{4-\mathrm{x}} \mathrm{Co}_{\mathrm{x}} \mathrm{Sb}_{12}$ with partial double filling of $\mathrm{La} / \mathrm{Yb}$ and substitution of $\mathrm{Co}$ at the $\mathrm{Fe}$ site and examined their thermoelectric properties.

\section{EXPERIMENTAL PROCEDURE}

Elemental La (purity 99.9\%, Kojundo), Yb (purity 99.9\%, Sigma Aldrich), Co (purity 99.95\%, Alfa Aesar), Fe (purity 99.95\%, Cerac), and $\mathrm{Sb}$ (purity 99.999\%, LTS) were weighed according to the stoichiometric compositions of $\left(\mathrm{La}_{1-\mathrm{z}} \mathrm{Yb}_{\mathrm{z}}\right)_{0.8} \mathrm{Fe}_{4-\mathrm{x}} \mathrm{Co}_{\mathrm{x}} \mathrm{Sb}_{12}(\mathrm{z}=0.25-0.75$ and $\mathrm{x}=0-1)$, and melted at $1323 \mathrm{~K}$ for $10 \mathrm{~h}$ in an evacuated quartz ampoule that was coated inside with carbon followed by water quenching. The obtained ingot was vacuum-sealed and annealed at $873 \mathrm{~K}$ for $24 \mathrm{~h}$. The ingot was ground into powder with a particle size of less than $75 \mu \mathrm{m}$. The powder was then charged in a graphite die and consolidated by hot pressing at $873 \mathrm{~K}$ for $1 \mathrm{~h}$ under $70 \mathrm{MPa}$.

The phases of the hot-pressed bodies were analyzed using $\mathrm{X}$-ray diffraction (XRD; Bruker, D8-Advance) with $\mathrm{Cu}-\mathrm{K}_{\alpha}$ radiation in the $\theta-2 \theta$ mode. Microstructures were observed using scanning electron microscopy (SEM; FEI, Quanta400), and atomic distributions were analyzed using energy dispersive spectroscopy (EDS; Oxford, JSM-5800). The electrical conductivity and Seebeck coefficient were simultaneously measured using the DC four-probe method with ZEM-3 (Ulvac-Riko) equipment. The thermal conductivity was evaluated from the measured thermal diffusivity, specific heat, and density using the laser flash method with TC-9000H (Ulvac-Riko) system. The measured Seebeck coefficient, electrical conductivity, and calculated thermal conductivity were used to evaluate the power factor and dimensionless ZT.

\section{RESULTS AND DISCUSSION}

XRD patterns of the $\left(\mathrm{La}_{1-\mathrm{z}} \mathrm{Yb}_{\mathrm{z}}\right)_{0.8} \mathrm{Fe}_{4-\mathrm{x}} \mathrm{Co}_{\mathrm{x}} \mathrm{Sb}_{12}$ skutterudites are presented in Fig. 1. The diffraction patterns were in good agreement with the standard diffraction data (PDF\# 56-1123)
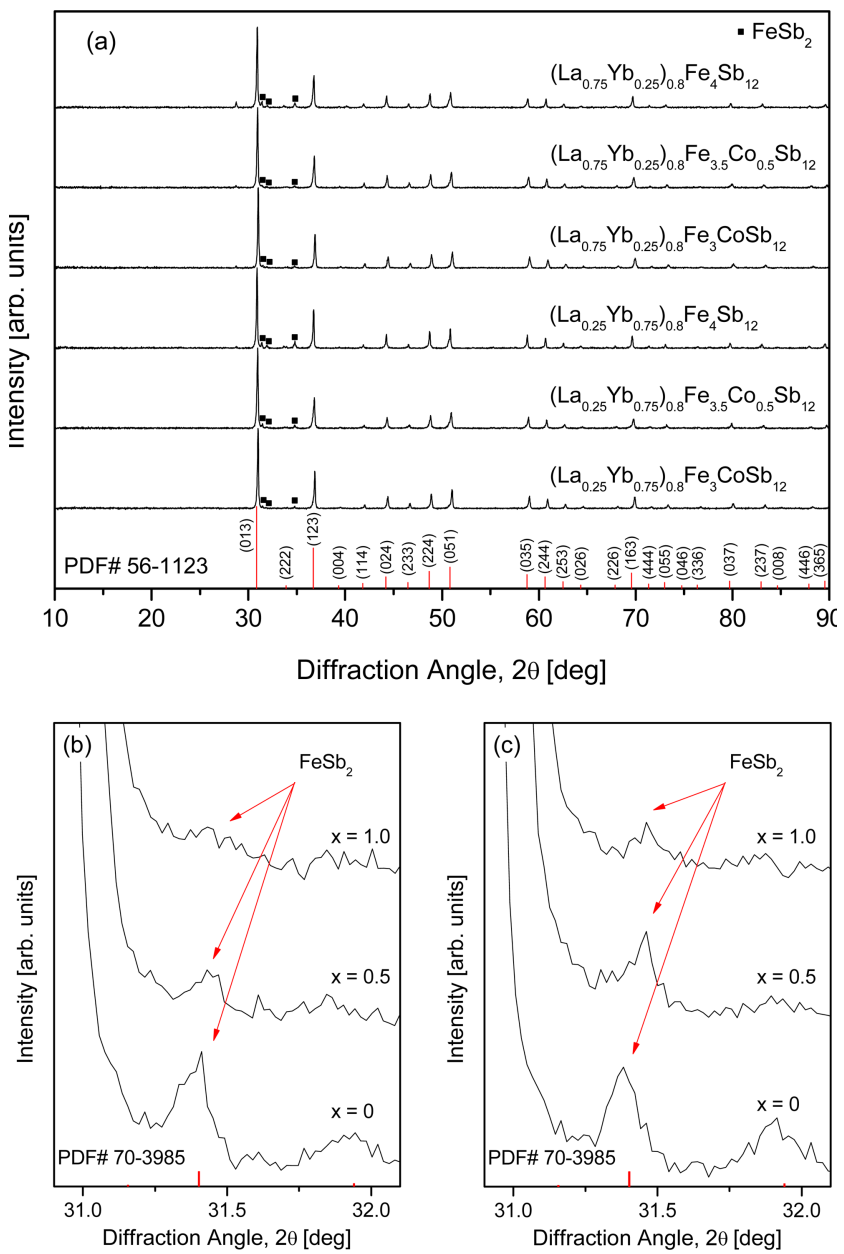

Fig. 1. XRD patterns of (a) the $\left(\mathrm{La}_{1-7} \mathrm{Yb}_{7}\right)_{0.8} \mathrm{Fe}_{4-\mathrm{x}} \mathrm{Co}_{\mathrm{x}} \mathrm{Sb}_{12}$ skutterudites and enlarged patterns of the specimens with (b) $\mathrm{z}=$ 0.25 and $(\mathrm{c}) \mathrm{z}=0.75$. 


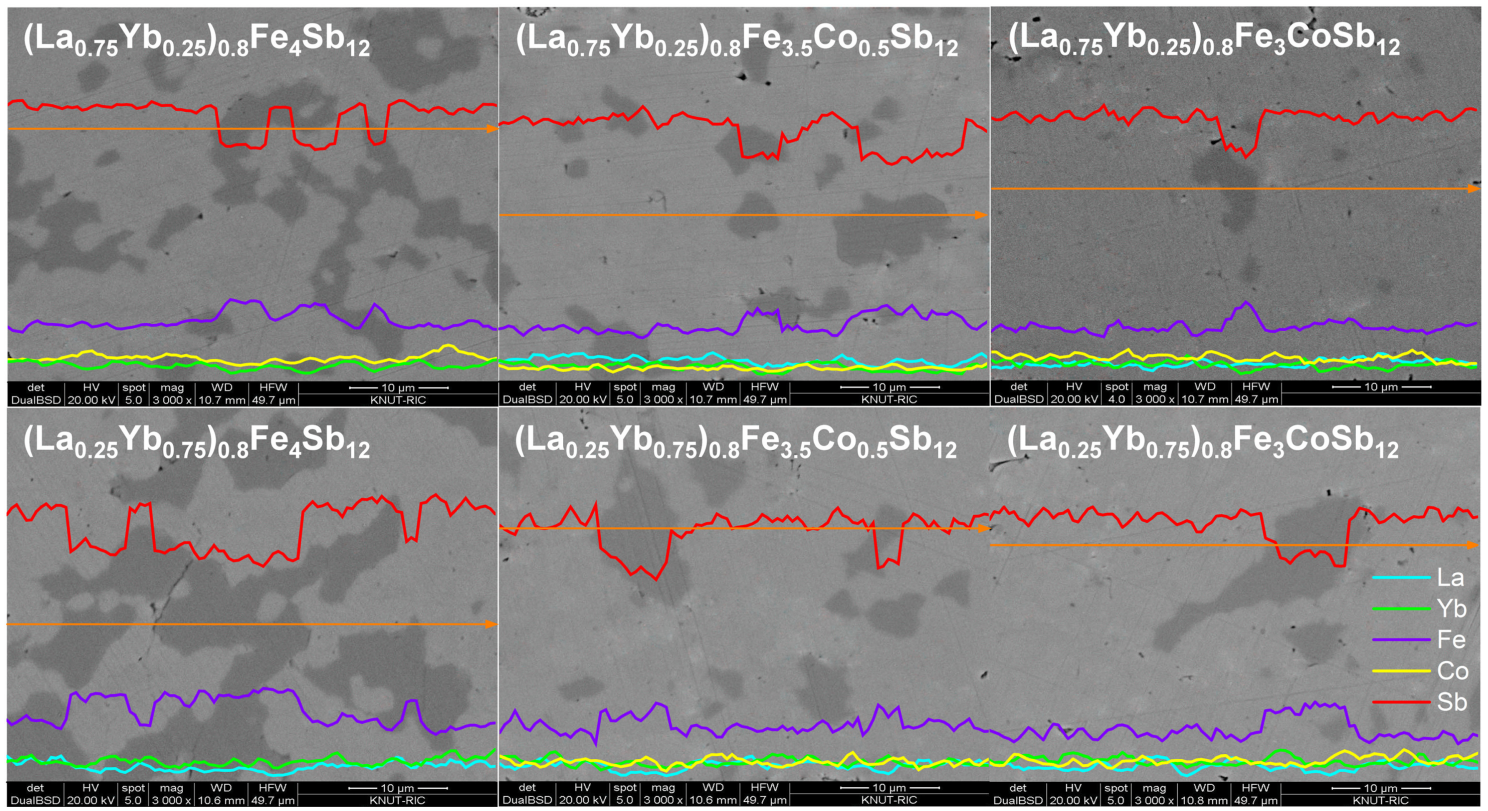

Fig. 2. SEM images and EDS line scans of $\left(\mathrm{La}_{1-\mathrm{z}} \mathrm{Yb}_{\mathrm{z}}\right)_{0.8} \mathrm{Fe}_{4-\mathrm{x}} \mathrm{Co}_{\mathrm{x}} \mathrm{Sb}_{12}$.

Table 1. Chemical compositions, relative densities, and lattice constants of $\left(\mathrm{La}_{1-\mathrm{z}} \mathrm{Yb}_{\mathrm{z}}\right)_{0.8} \mathrm{Fe}_{4-\mathrm{x}} \mathrm{Co}_{\mathrm{x}} \mathrm{Sb}_{12}$.

\begin{tabular}{ccccc}
\hline & Composition & & Relative Density & Lattice Constant \\
Nominal & Actual & & {$[\%]$} & [nm] \\
\hline$\left(\mathrm{La}_{0.75} \mathrm{Yb}_{0.25}\right)_{0.8} \mathrm{Fe}_{4} \mathrm{Sb}_{12}$ & $\mathrm{La}_{0.57} \mathrm{Yb}_{0.17} \mathrm{Fe}_{3.96} \mathrm{Sb}_{11.96}$ & 98.8 & 0.9138 \\
\hline$\left(\mathrm{La}_{0.25} \mathrm{Yb}_{0.75}\right)_{0.8} \mathrm{Fe}_{4} \mathrm{Sb}_{12}$ & $\mathrm{La}_{0.19} \mathrm{Yb}_{0.58} \mathrm{Fe}_{3.98} \mathrm{Sb}_{11.98}$ & 99.7 & 0.9142 \\
\hline$\left(\mathrm{La}_{0.75} \mathrm{Yb}_{0.25}\right)_{0.8} \mathrm{Fe}_{3.5} \mathrm{Co}_{0.5} \mathrm{Sb}_{12}$ & $\mathrm{La}_{0.57} \mathrm{Yb}_{0.16} \mathrm{Fe}_{3.49} \mathrm{Co}_{0.48} \mathrm{Sb}_{11.91}$ & 99.0 & 0.9134 \\
\hline$\left(\mathrm{La}_{0.25} \mathrm{Yb}_{0.75}\right)_{0.8} \mathrm{Fe}_{3.5} \mathrm{Co}_{0.5} \mathrm{Sb}_{12}$ & $\mathrm{La}_{0.15} \mathrm{Yb}_{0.56} \mathrm{Fe}_{3.49} \mathrm{Co}_{0.50} \mathrm{Sb}_{11.90}$ & 99.5 & 0.9139 \\
\hline$\left(\mathrm{La}_{0.75} \mathrm{Yb}_{0.25}\right)_{0.8} \mathrm{Fe}_{3} \mathrm{CoSb}_{12}$ & $\mathrm{La}_{0.54} \mathrm{Yb}_{0.18} \mathrm{Fe}_{2.98} \mathrm{Co}_{0.96} \mathrm{Sb}_{11.88}$ & 97.4 & 0.9129 \\
\hline$\left(\mathrm{La}_{0.25} \mathrm{Yb}_{0.75}\right)_{0.8} \mathrm{Fe}_{3} \mathrm{CoSb}_{12}$ & $\mathrm{La}_{0.18} \mathrm{Yb}_{0.57} \mathrm{Fe}_{2.95} \mathrm{Co}_{0.99} \mathrm{Sb}_{11.96}$ & 99.9 & 0.9131 \\
\hline
\end{tabular}

for the skutterudite phase, and a small quantity of the marcasite phase (PDF\# 70-3985) was identified. The diffraction peaks for the marcasite phase between $30.9^{\circ}$ and $32.1^{\circ}$ are enlarged in Figs. 1(b) and 1(c). The intensity of peak decreased with increasing Co substitution (x); this indicates that the skutterudite phase was stabilized by $\mathrm{Co}$ charge compensation. In addition, the diffraction peaks shifted to higher angles with increasing Co content because the smaller Co (atomic radius: $0.167 \mathrm{~nm}$ ) was substituted for the larger $\mathrm{Fe}$ (atomic radius: $0.172 \mathrm{~nm}$ ) site, which is consistent with the previous studies [17-19].

Figure 2 displays the SEM images and EDS analyses of $\left(\mathrm{La}_{1-\mathrm{z}} \mathrm{Yb}_{\mathrm{z}}\right)_{0.8} \mathrm{Fe}_{4-\mathrm{x}} \mathrm{Co}_{\mathrm{x}} \mathrm{Sb}_{12}$ skutterudites. The secondary phase was observed along with the main skutterudite phase; however, less secondary phase was observed with increasing
Co substitution. This was consistent with the XRD results. Charge compensation was confirmed to stabilize the skutterudite phase and suppress the formation of the secondary phase. In a previous study [20], the marcasite phase was observed in fully-filled $\mathrm{La}_{1-\mathrm{z}} \mathrm{Yb}_{\mathrm{z}} \mathrm{Fe}_{4-\mathrm{x}} \mathrm{Co}_{\mathrm{x}} \mathrm{Sb}_{12}$ skutterudites with $\mathrm{x} \leq 0.5$. However, in this study, the marcasite phase was detected in all specimens, which was because the charge compensation was not sufficiently performed owing to the partial filling with low valence ions of $\mathrm{La}^{3+}$ and $\mathrm{Yb}^{2+/ 3+}$ [21].

Chemical compositions, relative densities, and lattice constants of the $\left(\mathrm{La}_{1-\mathrm{z}} \mathrm{Yb}_{\mathrm{z}}\right)_{0.8} \mathrm{Fe}_{4-\mathrm{x}} \mathrm{Co}_{\mathrm{x}} \mathrm{Sb}_{12}$ are summarized in Table 1. After the completion of the preparation processes, the actual composition showed no significant difference from the nominal composition, and hot-pressed specimens showed 
relative densities higher than $97.4 \%$ compared to the theoretical density. The calculated lattice constant ranged from 0.9129 to $0.9142 \mathrm{~nm}$, and it decreased with increasing amount of La filling and Co substitution because the ionic radii are $\mathrm{Fe}(0.172 \mathrm{~nm}), \mathrm{Co}(0.167 \mathrm{~nm}), \mathrm{La}(0.136 \mathrm{~nm})$, and $\mathrm{Yb}(0.139 \mathrm{~nm})$ [22].

Figure 3 presents the temperature dependence of electrical conductivity for $\left(\mathrm{La}_{1-\mathrm{z}} \mathrm{Yb}_{\mathrm{z}}\right)_{0.8} \mathrm{Fe}_{4-\mathrm{x}} \mathrm{Co}_{\mathrm{x}} \mathrm{Sb}_{12}$. All specimens showed degenerate semiconductor behavior with decreasing electrical conductivity as the temperature increased. Lower electrical conductivity was obtained with increasing La filling and Co substitution. This resulted from the reduction in the carrier concentration caused by the difference in valences of $\mathrm{La} / \mathrm{Yb}$ and the charge compensation of Co. $\left(\mathrm{La}_{0.25} \mathrm{Yb}_{0.75}\right)_{0.8} \mathrm{Fe}_{4} \mathrm{Sb}_{12}$ showed the highest electrical conductivity of $2.48 \times 10^{5} \mathrm{Sm}^{-1}$ at $323 \mathrm{~K}$. The fully-filled $\mathrm{La}_{0.25} \mathrm{Yb}_{0.75} \mathrm{Fe}_{3.5} \mathrm{Co}_{0.5} \mathrm{Sb}_{12}$ exhibited a maximum electrical conductivity of $2.08 \times 10^{5} \mathrm{Sm}^{-1}$ at $323 \mathrm{~K}$ [20]; however, in this study, the partially-filled $\left(\mathrm{La}_{0.25} \mathrm{Yb}_{0.75}\right)_{0.8} \mathrm{Fe}_{3.5} \mathrm{Co}_{0.5} \mathrm{Sb}_{12}$ demonstrated higher electrical conductivity than the fullyfilled specimens.

The temperature dependence of the Seebeck coefficient for $\left(\mathrm{La}_{1-\mathrm{z}} \mathrm{Yb}_{\mathrm{z}}\right)_{0.8} \mathrm{Fe}_{4-\mathrm{x}} \mathrm{Co}_{\mathrm{x}} \mathrm{Sb}_{12}$ is shown in Fig. 4. All specimens displayed positive values of $\mathrm{p}$-type conductions. The Seebeck coefficient increased as the temperature increased, and it further increased with increasing $\mathrm{La}$ filling and Co substitution. This was due to the increased electron donation

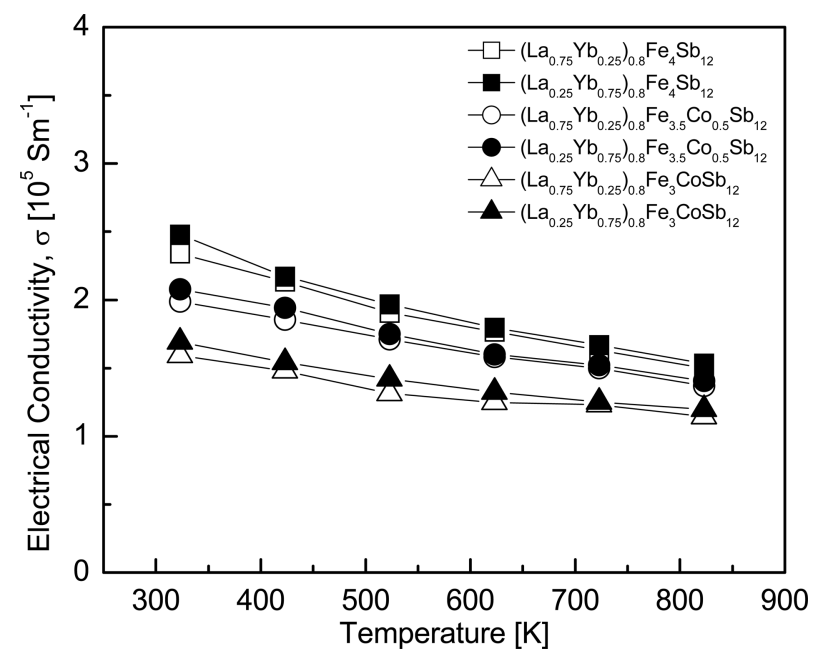

Fig. 3. Temperature dependence of the electrical conductivity for $\left(\mathrm{La}_{1-\mathrm{z}} \mathrm{Yb}_{\mathrm{z}}\right)_{0.8} \mathrm{Fe}_{4-\mathrm{x}} \mathrm{Co}_{\mathrm{x}} \mathrm{Sb}_{12}$. by $\mathrm{Yb}$ and the enhanced charge compensation by Co. $\left(\mathrm{La}_{0.75} \mathrm{Yb}_{0.25}\right)_{0.8} \mathrm{Fe}_{3} \mathrm{CoSb}_{12}$ yielded the highest Seebeck coefficient of $159.7 \mu \mathrm{VK}^{-1}$ at $823 \mathrm{~K}$, and the fully-filled $\mathrm{La}_{0.75} \mathrm{Yb}_{0.25} \mathrm{Fe}_{3} \mathrm{CoSb}_{12}$ exhibited a maximum Seebeck coefficient of $175.5 \mu \mathrm{VK}^{-1}$ at $723 \mathrm{~K}$ [20]. Thus, the partiallyfilled specimens showed lower Seebeck coefficient values than the fully-filled specimens with lower carrier concentrations.

Figure 5 presents the variations of the power factor with temperature and composition for $\left(\mathrm{La}_{1-\mathrm{z}} \mathrm{Yb}_{\mathrm{z}}\right)_{0.8} \mathrm{Fe}_{4-\mathrm{x}} \mathrm{Co}_{\mathrm{x}} \mathrm{Sb}_{12}$. As the temperature increased, the power factor increased and reached the maximum value at $723 \mathrm{~K}$. Higher power factor

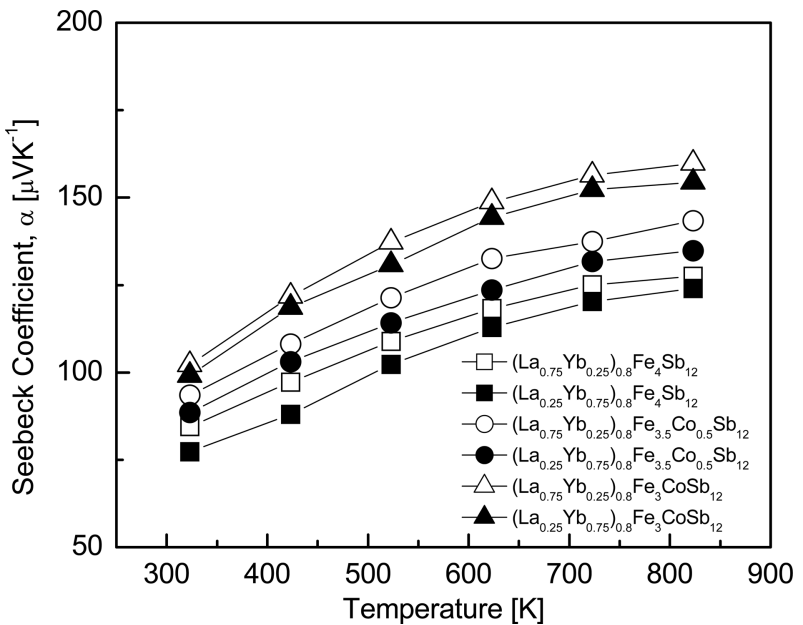

Fig. 4. Temperature dependence of the Seebeck coefficient for $\left(\mathrm{La}_{1-\mathrm{z}} \mathrm{Yb}_{\mathrm{z}}\right)_{0.8} \mathrm{Fe}_{4-\mathrm{x}} \mathrm{Co}_{\mathrm{x}} \mathrm{Sb}_{12}$.

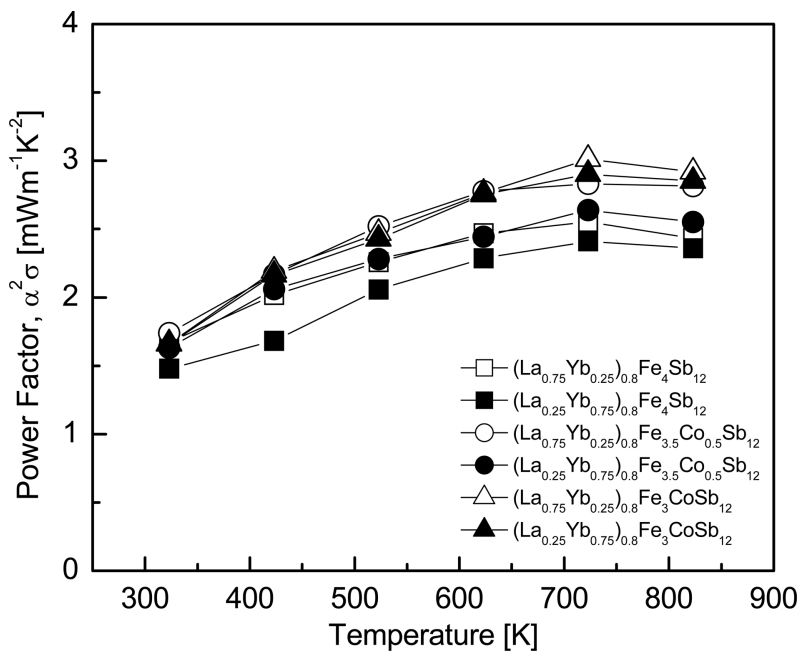

Fig. 5. Temperature dependence of the power factor for $\left(\mathrm{La}_{1-\mathrm{z}} \mathrm{Yb}_{\mathrm{z}}\right)_{0.8} \mathrm{Fe}_{4-\mathrm{x}} \mathrm{Co}_{\mathrm{x}} \mathrm{Sb}_{12}$. 
values were obtained with increasing La filling and Co substitution. However, the difference in the $\mathrm{La} / \mathrm{Yb}$ filling ratio did not significantly affect the power factor. $\left(\mathrm{La}_{0.75} \mathrm{Yb}_{0.25}\right)_{0.8} \mathrm{Fe}_{3} \mathrm{CoSb}_{12}$ exhibited maximum power factor of $3.01 \mathrm{mWm}^{-1} \mathrm{~K}^{-2}$ at $723 \mathrm{~K}$, which was higher than the power factor of $2.42 \mathrm{mWm}^{-1} \mathrm{~K}^{-2}$ at $723 \mathrm{~K}$ of the fully-filled $\mathrm{La}_{0.75} \mathrm{Yb}_{0.25} \mathrm{Fe}_{3} \mathrm{CoSb}_{12}$ [20].

The temperature dependence of the thermal conductivity for $\left(\mathrm{La}_{1-\mathrm{z}} \mathrm{Yb}_{\mathrm{z}}\right)_{0.8} \mathrm{Fe}_{4-\mathrm{x}} \mathrm{Co}_{\mathrm{x}} \mathrm{Sb}_{12}$ is shown in Fig. 6. The total thermal conductivity is shown in Fig. 6(a). The thermal conductivity apparently decreased with increasing Co substitution, and it was slightly lowered with increasing La filling. The increased thermal conductivity at temperatures above $623 \mathrm{~K}$ was due to the bipolar effect. $\left(\mathrm{La}_{0.75} \mathrm{Yb}_{0.25}\right)_{0.8} \mathrm{Fe}_{3} \mathrm{CoSb}_{12}$ showed the lowest thermal conductivity of $2.08 \mathrm{Wm}^{-1} \mathrm{~K}^{-1}$ at $323 \mathrm{~K}$, and the value was lower than $2.20 \mathrm{Wm}^{-1} \mathrm{~K}^{-1}$ at $523 \mathrm{~K}$ of the fullyfilled $\mathrm{La}_{0.75} \mathrm{Yb}_{0.75} \mathrm{Fe}_{3} \mathrm{CoSb}_{12}$ [20].

The electronic thermal conductivity is shown in Fig. 6(b). The Lorenz number was assumed to be $2.0 \times 10^{-8} \mathrm{~V}^{2} \mathrm{~K}^{-2}$. The electronic thermal conductivity decreased with increasing La filling and Co substitution with the same tendency as that of the total thermal conductivity. $\left(\mathrm{La}_{0.75} \mathrm{Yb}_{0.25}\right)_{0.8} \mathrm{Fe}_{3} \mathrm{CoSb}_{12}$ showed the lowest electronic thermal conductivity of 0.98 $\mathrm{Wm}^{-1} \mathrm{~K}^{-1}$ at $323 \mathrm{~K}$. The lattice thermal conductivity is shown in Fig. 6(c). The lowest values of $\kappa_{\mathrm{L}}=0.91-1.34 \mathrm{Wm}^{-1} \mathrm{~K}^{-1}$ were achieved in the temperature range of $623-823 \mathrm{~K}$. No significant change in the lattice thermal conductivity was found by varying the $\mathrm{La} / \mathrm{Yb}$ filling ratio, but the lattice thermal conductivity decreased with increasing Co substitution. This was due to the enhanced phonon scattering caused by the impurity scattering. $\left(\mathrm{La}_{0.25} \mathrm{Yb}_{0.75}\right)_{0.8} \mathrm{Fe}_{3} \mathrm{CoSb}_{12}$ showed the lowest lattice thermal conductivity of $0.91 \mathrm{Wm}^{-1} \mathrm{~K}^{-1}$ at $623 \mathrm{~K}$. In the case of the fully-filled $\mathrm{La}_{0.25} \mathrm{Yb}_{0.75} \mathrm{Fe}_{3} \mathrm{CoSb}_{12}$ [20], the minimum lattice thermal conductivity was reported to be $0.71 \mathrm{Wm}^{-1} \mathrm{~K}^{-1}$ at $723 \mathrm{~K}$. In this study, the lattice thermal conductivity slightly increased as a result of partial double filling. Enhanced phonon scattering was expected by the double filling of $\mathrm{La}$ and $\mathrm{Yb}$ to reduce the lattice thermal conductivity. However, the enhancement of phonon scattering was not significant owing to the similar atomic masses and ionic radii of $\mathrm{La}$ and $\mathrm{Yb}$, and the lattice thermal conductivity slightly increased over the fully-filled specimens.
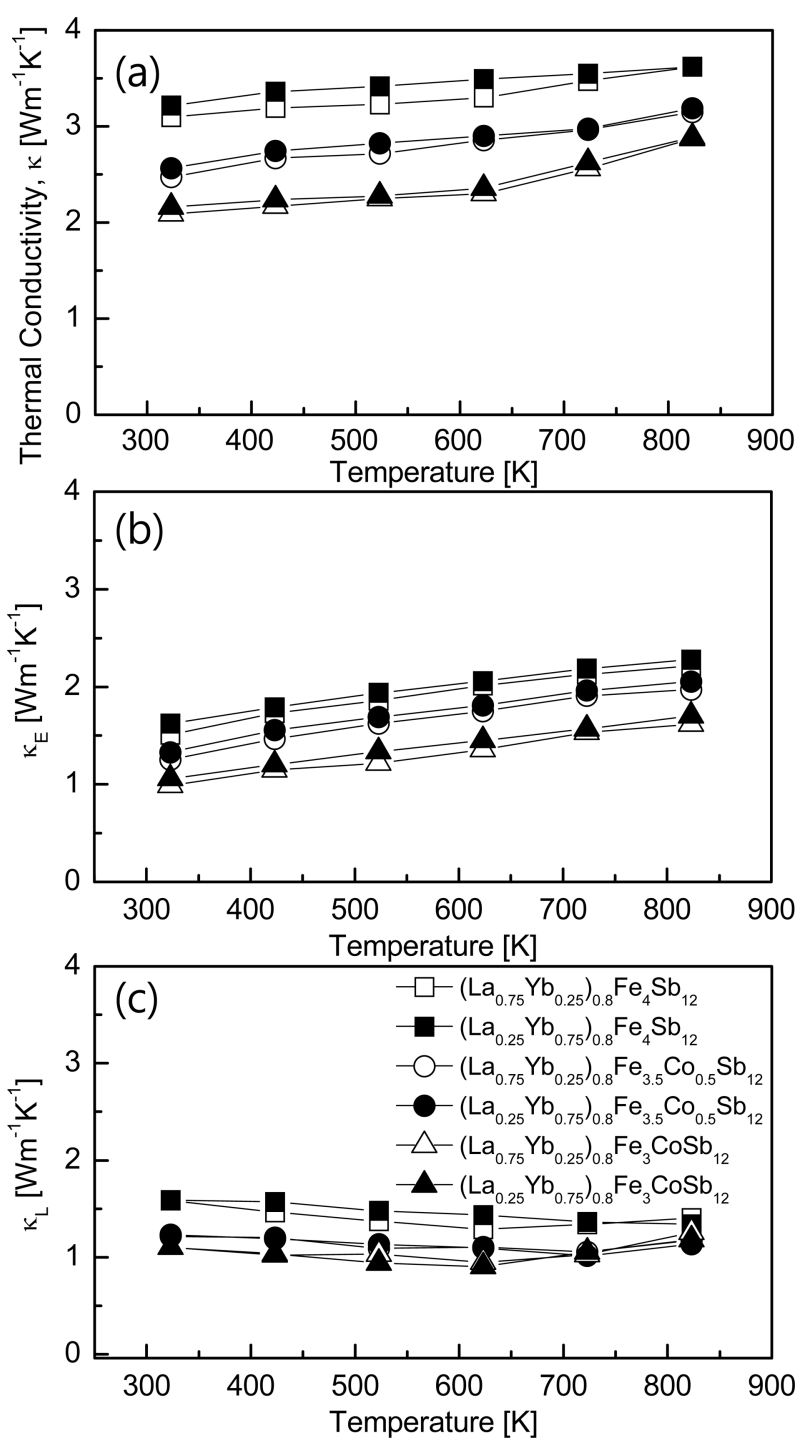

Fig. 6. Temperature dependence of the thermal conductivity for $\left(\mathrm{La}_{1-\mathrm{z}} \mathrm{Yb}_{\mathrm{z}}\right)_{0.8} \mathrm{Fe}_{4-\mathrm{x}} \mathrm{Co}_{\mathrm{x}} \mathrm{Sb}_{12}$ : (a) total thermal conductivity, (b) electronic thermal conductivity, and (c) lattice thermal conductivity.

Figure 7 presents the temperature dependence of the ZT for $\left(\mathrm{La}_{1-\mathrm{z}} \mathrm{Yb}_{\mathrm{z}}\right)_{0.8} \mathrm{Fe}_{4-\mathrm{x}} \mathrm{Co}_{\mathrm{x}} \mathrm{Sb}_{12}$. As the temperature increased, the $\mathrm{ZT}$ values increased and reached maximum values at temperatures between 723 and $823 \mathrm{~K}$. $\left(\mathrm{La}_{0.75} \mathrm{Yb}_{0.25}\right)_{0.8} \mathrm{Fe}_{3} \mathrm{CoSb}_{12}$ exhibited $\mathrm{ZT}_{\max }=0.83$ at $723 \mathrm{~K}$ owing to a higher power factor and a lower thermal conductivity. This value was higher than $\mathrm{ZT}_{\max }$ $=0.64$ at $723 \mathrm{~K}$ for the fully-filled $\mathrm{La}_{0.75} \mathrm{Yb}_{0.25} \mathrm{Fe}_{3} \mathrm{CoSb}_{12}$ [20]. Park et al. [23] reported $\mathrm{ZT}_{\max }=0.56$ at $823 \mathrm{~K}$ for single filled $\mathrm{LaFe}_{4} \mathrm{Sb}_{12}$ and Park et al. [24] further obtained $\mathrm{ZT}_{\text {max }}=0.59$ at $823 \mathrm{~K}$ for single filled $\mathrm{YbFe}_{4} \mathrm{Sb}_{12}$. In our previous studies on the $\mathrm{La} / \mathrm{Pr}$ - and $\mathrm{Ce} / \mathrm{Yb}$-partially-double- 


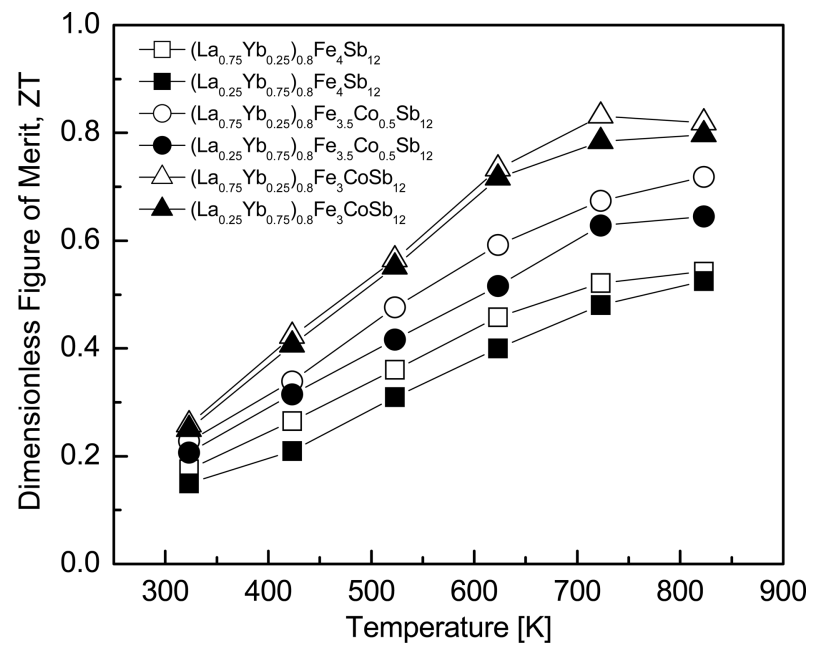

Fig. 7. Temperature dependence of the ZT for $\left(\mathrm{La}_{1-\mathrm{z}} \mathrm{Yb}_{\mathrm{z}}\right)_{0.8} \mathrm{Fe}_{4-\mathrm{x}} \mathrm{Co}_{\mathrm{x}} \mathrm{Sb}_{12}$.

filled skutterudites, $\mathrm{ZT}_{\max }=0.79$ was obtained at $723 \mathrm{~K}$ for $\left(\mathrm{La}_{0.25} \mathrm{Pr}_{0.75}\right)_{0.8} \mathrm{Fe}_{3.5} \mathrm{Co}_{0.5} \mathrm{Sb}_{12}$ [18] and $\mathrm{ZT}_{\max }=0.66$ was achieved at $823 \mathrm{~K}$ for $\left(\mathrm{Ce}_{0.25} \mathrm{Yb}_{0.75}\right)_{0.8} \mathrm{Fe}_{3.5} \mathrm{Co}_{0.5} \mathrm{Sb}_{12}$ [19]. However, Zhou et al. [25] reported high $\mathrm{ZT}_{\max }=0.99$ at 700 $\mathrm{K}$ for $\mathrm{La}_{0.60} \mathrm{Yb}_{0.25} \mathrm{Fe}_{2.7} \mathrm{Co}_{1.3} \mathrm{Sb}_{12}$. Therefore, in this study, partial double filling of $\mathrm{La} / \mathrm{Yb}$ and charge compensation of Co were effective for the improvement of thermoelectric performance, and further improvement is expected through precise control of the filling ratio and substitution.

\section{CONCLUSION}

$\mathrm{La} / \mathrm{Yb}$-partially-double-filled and Co-substituted $\left(\mathrm{La}_{1-\mathrm{z}} \mathrm{Yb}_{\mathrm{z}}\right)_{0.8}$ $\mathrm{Fe}_{4-\mathrm{x}} \mathrm{Co}_{\mathrm{x}} \mathrm{Sb}_{12}$ skutterudites were synthesized by encapsulated melting and hot pressing processes. A small quantity of the marcasite was detected as a secondary phase along with the skutterudite phase. However, the marcasite phase formation was suppressed by Co substitution. As La filling and Co substitution increased, the Seebeck coefficient increased while the electrical conductivity decreased. The thermal conductivity significantly decreased with increasing Co substitution, and was further slightly lowered with increasing La filling. Compared to the La/Yb-fully-filled skutterudites, the thermoelectric performance was improved because of a higher Seebeck coefficient and a lower thermal conductivity. $\left(\mathrm{La}_{0.75} \mathrm{Yb}_{0.25}\right)_{0.8} \mathrm{Fe}_{3} \mathrm{CoSb}_{12}$ showed a maximum $\mathrm{ZT}$ of 0.83 at $723 \mathrm{~K}$. Partial double filling of $\mathrm{La} / \mathrm{Yb}$ and charge compensation of Co improved the thermoelectric performance, and further enhancement is expected through precise composition design.

\section{ACKNOWLEDGMENTS}

This study was supported by the Industrial Core Technology Development Program funded by the Ministry of Trade, Industry and Energy (Grant No. 10083640), and by the Basic Science Research Capacity Enhancement Project (National Research Facilities and Equipment Center) through the Korea Basic Science Institute funded by the Ministry of Education (Grant No. 2019R1A6C1010047), Republic of Korea.

\section{REFERENCES}

1. L. D. Zhao, V. P. Dravid, and M. G. Kanatzidis, Energy Environ. Sci. 7, 251 (2014).

2. G. J. Tan, S. Y. Wang, G. Yan, H. Li, and X. F. Tang, J. Electron. Mater. 41, 1147 (2012).

3. T. Caillat, A. Borshchevsky, and J. P. Fleurial, J. Appl. Phys. 80, 4442 (1996).

4. C. Sales, D. Mandrus, B. C. Chakomakos, V. Keppens, and J. R. Thompson, Phys. Rev. B 56, 15081 (1997).

5. J. Yu, W. Y. Zhao, P. Wei, D. G. Tang, and Q. J. Zhang, J. Electron. Mater. 41, 1414 (2012).

6. L. D. Chen, T. Kawahara, X. F. Tang, T. Goto, T. Hirai, J. S. Dyck, W. Chen, and C. Uher, J. Appl. Phys. 90, 1864 (2001).

7. X. Shi, J. Yang, J. R. Salvador, M. F. Chi, J. Y. Cho, H. Wang, S. Q. Bai, J. H. Yang, W. Q. Zhang, and L. D. Chen, J. Am. Chem. Soc.133, 7837 (2011).

8. G. Rogl, A. Grytsiv, P. Rogl, E. Bauer, and M. Zehetbauer, Intermetallics 19, 546 (2010).

9. B. X. Chen, J. H. Xu, C. Uher, D. T. Morelli, G. P. Meisner, J. P. Fleurial, T. Caillat, and A. Borshchevsky, Phys. Rev. B 55, 1476 (1997).

10. S. Ballikaya, N. Uzar, S. Yildirim, H. Chi, X. L. Su, G. J. Tan, X. F. Tang, and C. Uher, J. Electron. Mater. 42, 1622 (2013).

11. G. A. Slack, Handbook of Thermoelectricity, edited by D. M. Rowe, p. 407, CRC, Boca Raton (1995).

12. X. Li, L. Chen, J. Fan, W. Zhang, T. Kawahara, and T. Hirai, J. Appl. Phys. 98, 3702 (2005). 
13. R. Carlini, A. U. Khan, R. Ricciardi, and T. Mori, J. Alloy. Compd. 655, 321 (2016).

14. R. Liu, J. Y. Cho, J. Yang, W. Zhang, and L. Chen, J. Mater. Sci. 30, 1134 (2014).

15. D. T. Morelli and G. P. Meisner, J. Appl. Phys. 77, 3777 (1995).

16. Q. Li, Z. W. Lin, and J. Zhou, J. Electron. Mater. 38, 1268 (2009).

17. Y. E. Cha and I. H. Kim, Korean J. Met. Mater. 56, 772 (2018).

18. Y. E. Cha and I. H. Kim, Korean J. Met. Mater. 57, 366 (2019).

19. D. Y. Choi, Y. E. Cha, and I. H. Kim, Korean J. Met. Mater.
56, 822 (2018).

20. G. S. Joo, D. K. Shin, and I. H. Kim, J. Electron. Mater. 44, 1383 (2015).

21. K. Yang, H. Cheng, H. H. Hng, J. Ma, J. L. Mi, X. B. Zhao, T. J. Zhu, and Y. B. Zhang, J. Alloy. Compd. 467, 528 (2009).

22. R. D. Shammon, Acta Crystallogr. A 32, 751 (1976).

23. K. H. Park, I. H. Kim, S. M. Choi, Y. S. Lim, W. S. Seo, and K. H. Kim, Jpn. J. Appl. Phys. 52, 10MB18 (2013).

24. K. H. Park, I. H. Kim, S. M. Choi, W. S. Seo, D. I. Cheong, and H. Kang, J. Electron. Mater. 42, 1377 (2013).

25. L. Zhou, P. F. Qiu, C. Uher, X. Shi, and L. D. Chen, Intermetallics 32, 209(2013). 